\title{
Functional analysis of the papilloma virus E2 trans-activator in Saccharomyces cerevisiae
}

\author{
Paul F. Lambert, ${ }^{1}$ Nathalie Dostatni, ${ }^{2}$ Alison A. McBride, ${ }^{1}$ Moshe Yaniv, ${ }^{2}$ Peter M. Howley, ${ }^{1}$ and \\ Benoit Arcangioli2 \\ ${ }^{1}$ Laboratory of Tumor Virus Biology, National Cancer Institute, Bethesda, Maryland 20892 USA; ${ }^{2}$ Department de Biologie \\ Moleculaire, URA 152 de Centre de la Recherche Scientifique, Institut Pasteur, 75724 Paris Cedex 15, France
}

The papilloma virus E2 transcriptional trans-activator is representative of a class of transcriptional modulators that activate transcription through direct binding to cis-acting DNA sequences. In this study we measured the capacity for this mammalian virus factor to function in Saccharomyces cerevisiae. When expressed in the yeast, the bovine papilloma virus E2 trans-activator could stimulate transcription from a yeast promoter having E2 DNA-binding sites present in cis. Whereas a single E2 DNA-binding site was sufficent for trans-activation, a strong cooperative effect was observed with two E2 DNA-binding sites. The level of trans-activation was dependent on the position of the E2 DNA-binding sites in relation to the yeast promoter, with the maximal effect demonstrated when the binding sites were positioned upstream. Deleted E2 proteins, lacking part of the trans-activation or DNA-binding domains, failed to activate transcription in yeast, similar to their behavior in mammalian cells. Replacement of the amino-terminal region of the E2 trans-activation domain with a synthetic amphipathic helix partially restored the trans-activation function; however, it did not result in a molecule that exhibited cooperativity between neighboring E2 DNA-binding sites.

[Key Words: Transcriptional trans-activation; S. cerevisiae; papilloma virus E2 gene; cooperativity]

Received October 3, 1988; revised version accepted November 28, 1988.

Recent studies have established that the transcriptional machinery of higher and lower eukaryotes is partially conserved. Several laboratories have shown the capacity for mammalian enhancers and cellular transcription factors to activate transcription in yeast (Harshman et al. 1988; Metzger et al. 1988; Schena and Yamamoto 1988 and yeast factors to function in mammalian cells (Kakidani and Ptashne 1988; Webster et al. 1988). Chodosh et al. (1988) found that subunits of the heterodimer Saccharomyces cerevisiae transcription factor, HAP2/ $H A P 3$, are functionally interchangeable with the subunits of the heterodimer mammalian transcription factor CP1A/CP1B. Others have shown the interchangeability of protein domains from the mouse and yeast RNA polymerase II large-subunit genes (Allison et al. 1988) or from avian oncoprotein iun and the yeast transactivator GCN4 (Struhl 1987). In this study we have asked whether a transcriptional trans-regulatory factor encoded by a mammalian virus might also function in yeast. We have also used $S$. cerevisiae as a host to study the mechanism of action of this protein, the papilloma virus E2 trans-activator.

The E2 trans-activator is one component of the E2 transcriptional control circuit encoded by papilloma viruses. Based on studies of bovine papilloma virus type 1 (BPV-1), viral transcription has been shown to be modulated by conditional enhancer elements, which are both activated (Spalholz et al. 1985) and repressed (Lambert et al. 1987a) by the several products encoded by the viral E2 open reading frame (ORF). The full-length E2 gene product, the E2 trans-activator (Spalholz et al. 1985; Yang et al. 1985), activates transcription at viral promoters (Haugen et al. 1987; Hermonat et al. 1988) by direct interaction with viral conditional enhancers, referred to as E2-responsive elements. This capacity to bind to specific sequences within the E2-responsive elements (Androphy et al. 1987; Moskulak and Bastia 1987; Giri and Yaniv 1988a,b) is presumed to be necessary for E2 trans-activation. The E2 ORF encodes two additional proteins, an amino terminally truncated E2 gene product generated by translational initiation at an internal ATG codon (Lambert et al. 1987a) and an E8/E2 gene product resulting from translation of a spliced mRNA species (Lambert et al. 1987b; M. Botchan, pers. comm.; P. Lambert and P. Howley, in prep.) These gene products are both transcriptional repressors which specifically inhibit the function of the EZ trans-activator. All three E2 proteins are expressed in BPV-1-transformed cells (Hubbert et al. 1988) and are capable of binding to the E2-responsive elements at the same repeated sequence, ACCN $_{6}$ GGT (McBride et al. 1988), as dimers (Dostatni et al. 1988; McBride et al. 1989). Two copies of this E2 DNA-binding site are sufficient to constitute an E2-dependent enhancer in mammalian cells (Harrison et al. 
1987; Hawley-Nelson et al. 1988; Spalholz et al. 1988|.

In this study the E2 trans-activator gene was placed under the control of the regulatable PHO5 yeast promoter, and E2 trans-activation activity was assayed using a $\beta$-galactosidase expression plasmid in which $\beta$ galactosidase expression was driven off a chimeric promoter containing E2 DNA-binding sites positioned upstream from the minimal $C Y C 1$ yeast promoter. Expression of the E2 trans-activator was detected in yeast and shown to result in E2 enhancer-specific expression of $\beta$ galactosidase. This system was used to determine the functional role of different domains of the E2 protein. Based on this study, both similarities and differences were observed in the requirements for E2-dependent transcriptional trans-activation in yeast versus mammalian cells. In addition, insight into the mechanism for cooperativity is discussed with respect to the role of DNA-binding affinity and to potential differences in the trans-activational capacity of singly versus tandemly bound E2 dimers.

\section{Results}

\section{E2 expression and trans-activation in S. cerevisiae}

To determine the capacity of the BPV-1 E2 transcriptional trans-activator to function in yeast, plasmids were constructed that placed one (pDUAS: $1 \mathrm{mtf}$ ) or two (pDUAS:2mtf) copies of the E2 DNA-binding site upstream of the CYC1 promoter deleted for its UAS sequences ( $p \Delta U A S$ plasmid series; Fig. 1A). In mammalian cells, two copies of the E2 DNA-binding site are sufficient to act as an E2 trans-activator-dependent transcriptional enhancer. The chimeric E2 enhancer/CYC1 promoter in these $2 \mu$ plasmids was positioned upstream of the Escherichia coli $L A C Z$ gene, which encodes the assayable enzyme $\beta$-galactosidase. The E2 trans-activator gene was placed behind the yeast $\mathrm{PHO} 5$ promoter, which regulates expression of the inducible $P H O 5$, alkaline phosphatase gene. Under high phosphate levels, this promoter is repressed, whereas under low phosphate levels, the promoter is transcriptionally derepressed (Rogers et al. 1982). The PHO5 promoter/E2 trans-activator gene cassette was cloned into the high-copynumber, $2 \mu$ shuttle vector (pPD2 plasmid series; Fig. 1B) to give the plasmid pPD2-E2. It was also inserted into an ARS/centromeric plasmid shuttle vector /p $\triangle Y A C$ plasmid series; Fig. $1 \mathrm{C}$ ) to give the plasmid p $\triangle \mathrm{YAC}$ :E2. Yeast strains were transfected with these plasmids by the lithium acetate-polyethylene glycol (PEG) method (Ito et al. 1983), and colonies selected for plasmid-encoded markers.

To detect E2 expression in yeast, transfectant cells (strain SX4-6A) were labeled metabolically using $\left.{ }^{35} \mathrm{~S}\right]$ methionine and protein extracts immunoprecipitated with E2-specific antisera. As seen in Figure 2 (lane 3 ), an E2 antisera-specific polypeptide of $\sim 48 \mathrm{kD}$ was detected in cells harboring the plasmid p $\triangle Y$ YAC-E2 grown under $P H O-5$-induced conditions. This polypeptide was not detected in cells harboring p $\triangle$ YAC-E2 grown under PHO5-repressed conditions (Fig. 2, lane 2) nor in cells harboring the parent expression vector p $\triangle$ YAC grown under induced conditions (Fig. 2, lane 1). The 48-kD E2-specific polypeptide has the same gel mobility as the full-length E2 gene product generated by in vitro translation of the full-length E2 mRNA /data not shown). A nonspecific, yeast-encoded, $50-\mathrm{kD}$ protein was cross-reactive to our E2 peptide-generated antisera (Fig. 2, lanes 1-3). Western blot analysis using E2-specific antisera (provided by Dr. D. Lowy) showed the presence of a single band of $48 \mathrm{kD}$ in pPD2E2 harboring cells, which was 10- to 15 -fold more abundant under low phosphate conditions (B. Arcangioli, unpubl.).

The E2 trans-activator binds as a homodimer to a single E2 DNA-binding site, multiple copies of which are present in the papilloma virus E2 conditional enhancers (Dostatni et al. 1988; McBride et al. 1988). Gel retardation assays were performed to test the DNAbinding capacity of the E2 protein expressed in yeast. Crude extracts were prepared from pPD2-E2 transfectant yeast (strain BWG1-7a) grown under high or low phosphate conditions, as described in Table 3 . The probe for the gel retardation experiment was a double-stranded, ${ }^{32}$ P-end-labeled oligonucleotide containing a single E2 DNA-binding site. Whereas low levels of E2-specific DNA-binding activity were detected in extracts from yeast grown under noninduced conditions (Fig. 3, high $\left.\mathrm{P}_{\mathrm{i}}\right), \sim 20$-fold higher levels of binding activity were detected under induced conditions (Fig. 3, low $P_{i}$ ). No DNA-binding activity was detected in extracts from control yeast strains (data not shown). Thus, the E2 protein expressed in yeast has the capacity to bind specifically to the E2 DNA-binding motif.

To determine whether the E2 protein expressed under control of the PHO5 promoter was competent to activate transcription through its DNA-binding sites, yeast (strain BWG1-7A) was cotransfected with the E2-expressing plasmid, pPD2E2, and the lacZ reporter plasmid

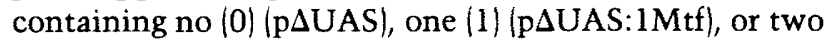
(2) (pDUAS:2mtf) copies of the E2 DNA-binding site positioned upstream of the minimal $C Y C 1$ promoter. Individual colonies were streaked onto nitrocellulose filters resting on selective medium agar containing low phosphate and grown for $48 \mathrm{hr}$. The filters were then transferred to agar plates containing the $\beta$-galactosidase chromogenic substrate $\mathrm{X}-\mathrm{Gal}$ and incubated at $30^{\circ} \mathrm{C}$ for $5 \mathrm{hr}$. Figure 4 illustrates the capacity of E2 to trans-activate the lac $Z$ gene. $\beta$-Galactosidase activity was detected in cells harboring either $\mathrm{p} \Delta \mathrm{UAS}: 1 \mathrm{mtf}$ or $\mathrm{p} \Delta \mathrm{UAS}: 2 \mathrm{mtf}$, with stronger expression occurring with the latter plasmid. These results indicate that the E2 protein expressed in yeast not only binds to its DNA target but also is competent for trans-activation.

To quantitate the extent of E2 trans-activation in yeast, transfectants were assayed for $\beta$-galactosidase activity in liquid culture under conditions of $P H O 5$ promoter induction. In the absence of the E2 trans-activator, low levels of $\beta$-galactosidase activity were detected (Table 1, lines 1-7). A weak but reproducible increase in basal expression of $\beta$-galactosidase was noted with the double-motif insert $\mathrm{p} \Delta \mathrm{UAS}: 2 \mathrm{mtf}$ in the absence of E2, when compared to the parent vector pDUAS 


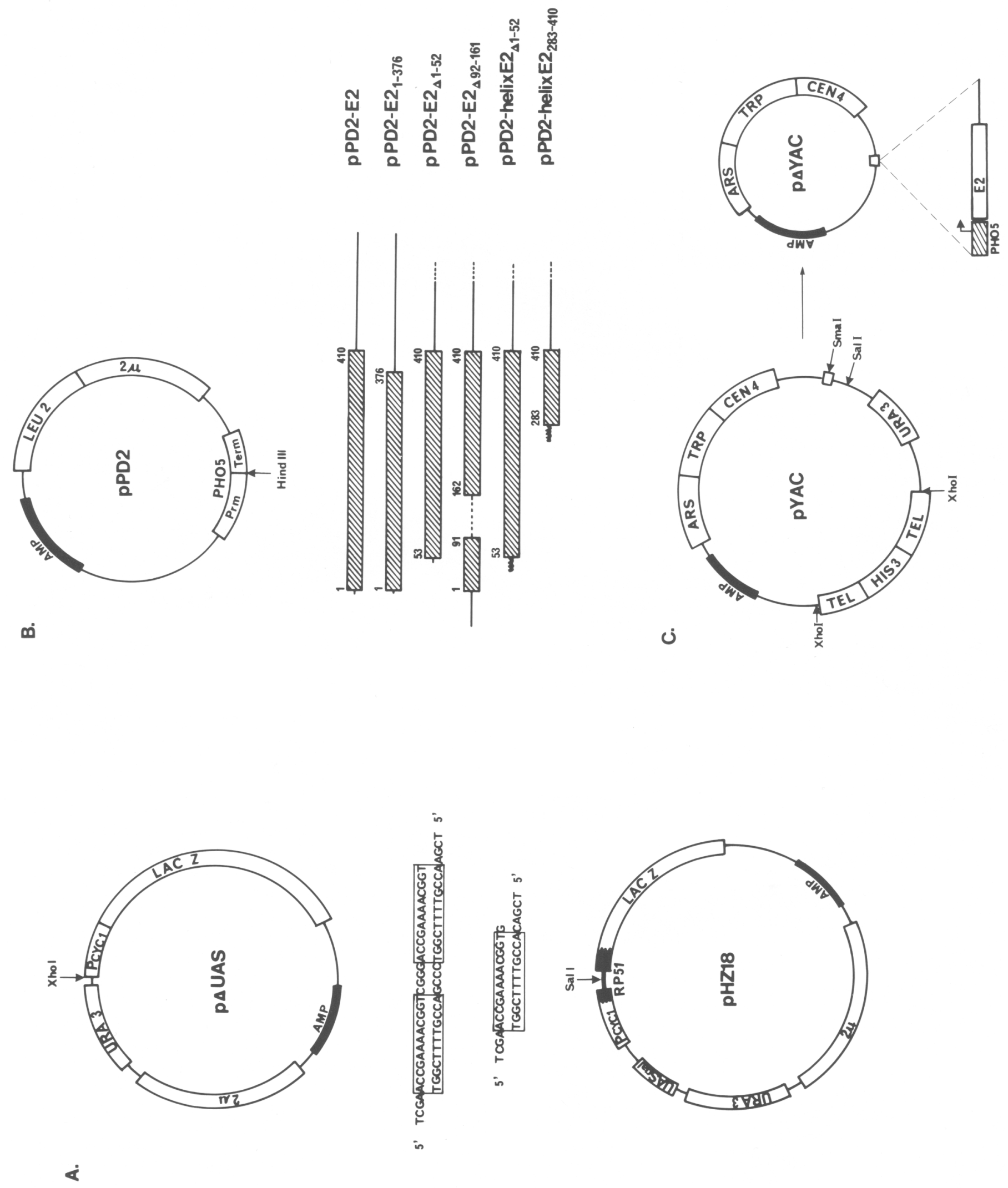

Figure 1. (See facing page for legend.) 


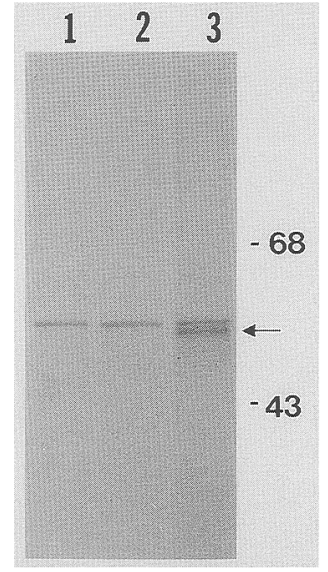

Figure 2. E2 immunoprecipitation. Yeast strain SX4-6A, harboring $\mathrm{p} \triangle \mathrm{YAC}$ or $\mathrm{p} \triangle \mathrm{YAC}-\mathrm{E} 2$, was grown in defined medium containing either high (1000 mg/liter) or low $(30 \mathrm{mg} / \mathrm{liter})$ concentrations of $\mathrm{P}_{\mathrm{i}}$ and metabolically labeled with $\left.{ }^{35} \mathrm{~S}\right]$ methionine. E2 polypeptides were immunoprecipitated with E2-specific antisera and resolved by SDS-PAGE: (Lane 1) Cells harboring $\mathrm{p} \triangle \mathrm{YAC}$ grown under induced (low $\mathrm{P}_{\mathrm{i}}$ ) conditions; (lane 2) cells harboring $\mathrm{p} \triangle \mathrm{YAC}-\mathrm{E} 2$ grown under uninduced (high $\mathrm{P}_{\mathrm{i}}$ ) conditions; (lane 3) cells harboring $\mathrm{p} \triangle \mathrm{YAC}-\mathrm{E} 2$ grown under induced (low $\left.P_{i}\right)$ conditions. $(\rightarrow)$ The E2 antisera-specific $48-k D$ band.

(Table 1, line 4 versus 2 and line 7 versus 5 ), the significance of which is not clear at this time. High-level expression of $\beta$-galactosidase activity was detected in yeast harboring the E2 trans-activator-expressing plasmid pPD2-E2 and the $\beta$-galactosidase plasmid $\mathrm{p} \Delta \mathrm{UAS}: 2 \mathrm{mtf}$ (Table 1, line 10). Either the absence of E2 DNA-binding sites in cis (Table 1, line 8) or of E2 trans-activator in trans (Table 1, line 7) resulted in basal levels of $\beta$-galactosidase activity. E2-dependent expression was also seen with pDUAS: $1 \mathrm{mtf}$; however, the presence of two motifs of the E2 DNA-binding site resulted reproducibly in 20fold higher levels of $\beta$-galactosidase activity (Table 1, line 10 versus 9 ; the induction ratio varied between 15 . and 20 -fold in numerous assays performed). This cooperative effect of multiple E2-binding motifs has been documented in mammalian cells (Spalholz et al. 1988). A significant difference between yeast and mammalian cells, however, is the capacity for a single motif to act as a weak E2-dependent enhancer in yeast, a property not noted in mammalian cells (Hawley-Nelson et al. 1988; Hirochika et al. 1988; Spalholz et al. 1988). Although this difference may reflect an increased sensitivity in the yeast assay and/or higher levels of E2 expression in yeast as compared with mammalian cells, it is also possible that this difference reflects a mechanistic difference in the requirements for E2 trans-activation. The absolute level of E2-dependent $\beta$-galactosidase activity obtained with $\mathrm{p} \Delta U A \mathrm{US}: 2 \mathrm{mtf}$ was equal to that measured with the intact CYC1 promoter/activator under induced conditions (B. Arcangioli and R. Sousa, unpubl.). Thus, the E2-activated promoter is among the strongest promoters existing in S. cerevisiae. Even the activity detected with the one motif compares to that of an average yeast promoter.

\section{Assessment of papilloma virus E2 functional domains required for trans-activation}

To define the domains of the E2 protein involved in trans-activation, several mutant $\mathrm{E} 2$ genes with deletions (pPD2-E2 $2_{\Delta 1-52,}$ pPD2-E2 $2_{\Delta 92-161}$ ) or an oligonucleotide insertion (pPD2-E2 $2_{1-376}$ ), which introduces a premature translational termination codon within the E2 gene, were inserted into the pPD2 vector (Fig. 1B). These same mutations render the E2 trans-activator nonfunctional in mammalian cells (McBride et al. 1988). The in-frame deletions lie within the amino-terminal trans-activation domain of E2 - the first removing one region of potential amphipathic helix structure and the second leaving these regions intact - and the oligonucleotide insertion truncates the E2 protein within the carboxy-terminal, DNA-binding/dimerization domain (see Fig. 5). These mutant E2 proteins were also incapable of trans-activating in yeast harboring $\mathrm{p} \Delta \mathrm{UAS}: 2 \mathrm{mtf}$ (Table 1 , lines $11-13$ ). Thus, the integrity of the amino-terminal transactivation domain and carboxy-terminal DNA-binding and dimerization domain are essential for the trans-activation function in yeast as they are in mammalian cells.

A DNA sequence encoding a previously described, model amphipathic helix (Giniger and Ptashne 1987) was placed upstream of the carboxy-terminal region of the E2 ORF encoding the E2 DNA-binding/dimerization domain (pPD2-helix:E2 $283-410$ ). This amphipathic helix is predicted to have one hydrophobic face and another hydrophilic face bearing negatively charged, acidic res-

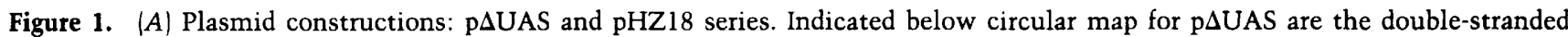
synthetic oligonucleotides containing either one (bottom sequence) or two (top sequence) E2 DNA-binding sites, which were inserted upstream form the $\mathrm{P}_{\mathrm{CYCl}}$ promoter, at the unique $X$ hoI site, to give $\mathrm{p} \triangle \mathrm{UAS}: 1 \mathrm{mtf}$ and $\mathrm{p} \Delta \mathrm{UAS}: 2 \mathrm{mtf}$, respectively. Positions of the AMP, $L A C Z, \mathrm{P}_{\text {cycl } 1}, 2 \mu$, and $U R A 3$ genetic elements are indicated. The same oligonucleotides were inserted into the unique Sall site in

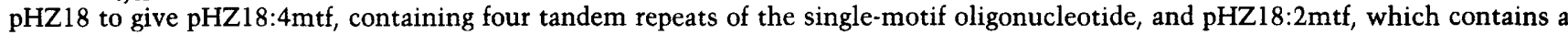
single copy of the double-motif oligonucleotide. $(B)$ Plasmid constructions: pPD2 series. Indicated below the pPD2 circular map are the DNA fragments containing the BPV-1 E2 ORF or mutated versions that were inserted into the HindIII site of pPD2. pPD2-E2 encodes the wild type, and the mutants have been designated according to which amino acids from the full-length E2 protein are present (see legend to Fig. 4). Indicated in the pPD2 map are the genetic elements: AMP, LEU2, $2 \mu$, and the PHO5 promoter ( $\mathrm{P}_{\mathrm{RM}}$ ) and terminator $($ Term $) .(C)$ Plasmid constructions: $\mathrm{p} \triangle \mathrm{YAC}$ series. The vector $\mathrm{p} \triangle \mathrm{YAC}$ was generated from the larger plasmid $\mathrm{pYAC}$ by cleaving the SalI and XhoI and religating. The BamHI fragment from pPD2-E2, containing the PHO5 promoter and wild-type E2 ORF, was inserted into the SmaI cloning site of $\mathrm{p} \Delta \mathrm{YAC}$. 
Figure 3. Binding of BPV-1 E2 expressed in yeast to its target DNA. Band-shift assays were performed with extracts of cells grown under conditions of high or low $P_{i}$, as indicated. Different amounts of protein were incubated with $0.5 \mathrm{ng}$ of the following ${ }^{32}$ P-end-labeled double-stranded oligonucleotide containing one E2 DNA-binding site in the presence of $100 \mathrm{ng}$ of sonicated salmon sperm DNA, $0.5 \mu \mathrm{g}$ of poly $(\mathrm{dI}-\mathrm{dC})$, and $0.1 \% \mathrm{NP}-40$.

\section{CTAGACCGAAAACGGTGCTAG GATCTGGCTTTTGCCACGATC}

(C1) The specific E2-DNA complex. Minor bands that appear at high protein concentrations prove to be nonspecific, as evidenced by their loss under conditions of increased concentrations of nonspecific competitor DNA (see Fig. 6).

idues. When expressed in yeast, this fusion protein gave very low trans-activation activity (Table 1 , lines 14 and 15), which was dependent on the E2 DNA-binding sites. A threefold higher level of trans-activation was obtained with a fusion protein in which this amphipathic helix was placed upstream of the amino-terminally truncated E2 gene present in the trans-activation-deficient E2 mutant, pPD2-E2 $2_{\Delta 1-52}$ (Table 1, lines 16 and 17). The in creased trans-activational activity of $\mathrm{pPD} 2$-helix:E2 $2_{\Delta 1}$. ${ }_{52}$, as compared with pPD2-helix:E2 $283-410$, likely reflect: the contribution of the additional portion of the $E$ ? trans-activation domain between $\mathrm{E} 2$ amino acids 53 an 282 present in the former plasmid (see Fig. 5). This do main of the E2 protein clearly has a role in trans-activa tion in mammalian cells (Giri and Yaniv 1988b; McBride et al. 1989/ and in yeast, as demonstrated by the defective nature of $\mathrm{pPD} 2-\mathrm{E} 2_{\Delta 92-161}$ in trans-activation (Table 1, line 12). Neither construct containing the model amphipathic domain exhibited the cooperative effect seen with wild-type E2 protein and the doublemotif plasmid pDUAS:Zmtf. This indicates that the cooperative effect of E2 observed in yeast can be separated from the trans-activation capacity.

Both the p $\triangle$ UAS and pPD2 plasmid series use the $2 \mu$ yeast replicon. Because of the potential for plasmid instability and/or recombination in the cotransfectant yeast, the $\mathrm{PHO} / \mathrm{E} 2$ trans-activator cassette from $\mathrm{pPD} 2$ E2 was recloned into $\mathrm{p} \triangle \mathrm{YAC}$, an ARS/centromeric plasmid shuttle vector (Fig. 1C). The resulting plasmid $\mathrm{p} \triangle \mathrm{YAC}: \mathrm{E} 2$ and the parent vector $\mathrm{p} \triangle \mathrm{YAC}$ were each transfected into strain SX4-6A along with the pDUAS series plasmids, and the resulting yeast colonies were assayed for E2-induced $\beta$-galactosidase activity (Table 2). Under induced conditions, $\mathrm{p} \Delta \mathrm{YAC}-\mathrm{E} 2$ gave rise to high levels of $\beta$-galactosidase expression (Table 2 , lines 5 and 6) from the $\mathrm{p} \Delta \mathrm{UAS}: 2 \mathrm{mtf}$ plasmid. Cooperativity was evidenced by the 20-fold lower levels of E2-dependent $\beta$-galactosidase expression in cells harboring the single-

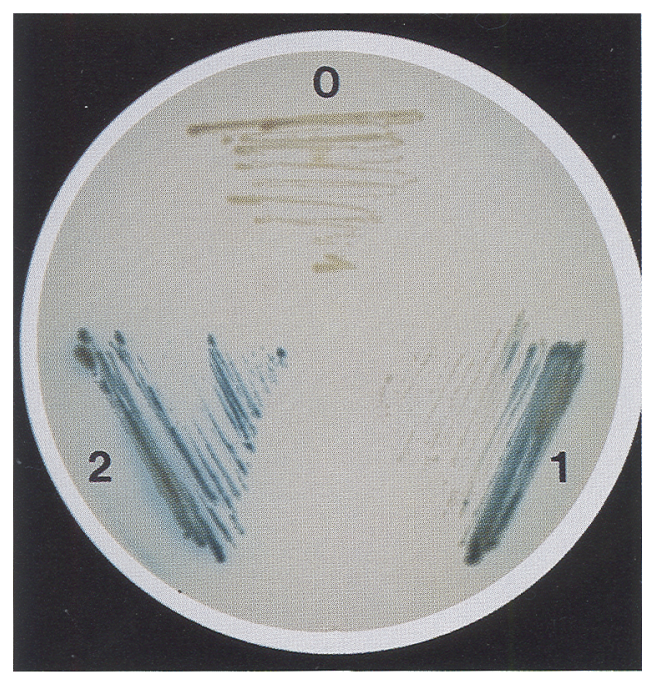

Figure 4. $\mathrm{X}$-Gal plate. $\beta$-Galactosidase expression as detected by cleavage of the chromogenic substrate $\mathrm{X}$-Gal. Plate contains BWG1-7a transfected with pPD2-E2 and either pDUAS $(\mathrm{O}$, top

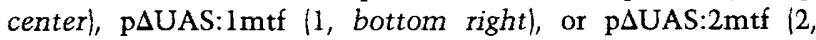
bottom left) (for details, see Materials and methods). 
Table 1. Genetic requirements for E2-dependent expression in S. cerevisiae $B W G 1-7 A$

\begin{tabular}{|c|c|c|c|}
\hline & $\mathrm{DNA}_{1}$ & $\mathrm{DNA}_{2}$ & $\begin{array}{l}\beta \text {-Galactosidase } \\
\text { activity } \\
\text { (units) }^{\mathbf{a}}\end{array}$ \\
\hline 1. & - & - & 0.010 \\
\hline 2. & $\mathrm{p} \Delta \mathrm{UAS}$ & - & 0.075 \\
\hline 3. & $\mathrm{p} \Delta \mathrm{UAS}: 1 \mathrm{mtf}$ & - & 0.090 \\
\hline 4. & $\mathrm{p} \Delta \mathrm{UAS}: 2 \mathrm{mtf}$ & - & 0.490 \\
\hline 5. & $\mathrm{p} \Delta \mathrm{UAS}$ & pPD2 & 0.070 \\
\hline 6. & pDUAS: $1 \mathrm{mtf}$ & pPD2 & 0.110 \\
\hline 7. & $\mathrm{p} \Delta \mathrm{UAS}: 2 \mathrm{mtf}$ & pPD2 & 1.10 \\
\hline 8. & $\mathrm{p} \Delta \mathrm{UAS}$ & pPD2-E2 & 0.090 \\
\hline 9. & pDUAS: $1 \mathrm{mtf}$ & pPD2-E2 & 4.3 \\
\hline 10. & $\mathrm{p} \Delta \mathrm{UAS}: 2 \mathrm{mtf}$ & pPD2-E2 & 94.0 \\
\hline 11. & $\mathrm{p} \triangle \mathrm{UAS}: 2 \mathrm{mtf}$ & $\mathrm{pPD} 2-\mathrm{E} 2 / \Delta 1-52$ & 1.3 \\
\hline 12. & $\mathrm{p} \Delta \mathrm{UAS}: 2 \mathrm{mtf}$ & $\mathrm{pPD} 2-\mathrm{E} 2 /_{\Delta 92-161}$ & 1.7 \\
\hline 13. & $\mathrm{p} \Delta \mathrm{UAS}: 2 \mathrm{mtf}$ & $\mathrm{pPD} 2-\mathrm{E} 2 /_{1-376}$ & 0.31 \\
\hline 14. & pDUAS: $1 \mathrm{mtf}$ & pPD2-helix:E2 $283-410$ & 3.6 \\
\hline 15. & pDUAS: $2 \mathrm{mtf}$ & pPD2-helix:E2 $283-410$ & 4.9 \\
\hline 16. & pDUAS: $1 \mathrm{mtf}$ & pPD2-helix:E2 $2_{\Delta 1-52}$ & 13.5 \\
\hline 17. & $\mathrm{p} \Delta \mathrm{UAS}: 2 \mathrm{mtf}$ & pPD2-hleix:E2 $2_{\Delta 1-52}$ & 12.0 \\
\hline
\end{tabular}

a Fresh overnight cultures $(1 \mathrm{ml})$ grown in SD media were spun to pellet cells, the cells washed once, and then resuspended in $10 \mathrm{ml}$ of phosphate-depleted SD media. $\beta$-Galactosidase assays were performed after growth to an $\mathrm{OD}_{600}$ of $0.4-0.6$. motif plasmid $\mathrm{p} \Delta \mathrm{UAS}: 1 \mathrm{mtf}$. These results confirm the results obtained in strain BWG1-7a using the $2 \mu$ vector pPD2.

\section{Dependence of enhancer location}

Whereas transcriptional enhancers identified in mammalian cells are capable of functioning in a relatively orientation- and position-independent manner, the upstream activating sequences of yeast function only when placed close to and upstream from a yeast promoter (Guarente and Hoar 1984). In the original set of $\beta$-galactosidase expression plasmids, pDUAS series, the E2 DNA-binding motifs were placed just upstream from the CYC1 promoter in place of the UAS sequences. To determine whether the $\mathrm{E} 2$ enhancer can function in yeast in a distance- and location-independent manner, E2 DNA-binding motifs were introduced into an intron that had been constructed previously within the $L A C Z$ gene (see pHZ18, Fig. 1A). Expression of $L A C Z$ in pHZ18 requires RNA initiation in the CYC1 promoter (Guarente and Hoar 1984). These plasmids, pHZ18:2mtf and pHZ18:4mtf, containing either two or four copies of the E2 motif, were assayed in SX4-6A cells harboring $\mathrm{p} \triangle \mathrm{YAC}$ or $\mathrm{p} \triangle \mathrm{YAC}: \mathrm{E} 2$. Low but reproducible E2-dependent $\beta$-galactosidase expression was detected (Table 2, lines 7-12). This represented approximately a sevenfold increase over the basal-level expression for both $\mathrm{pHZ18}$ :
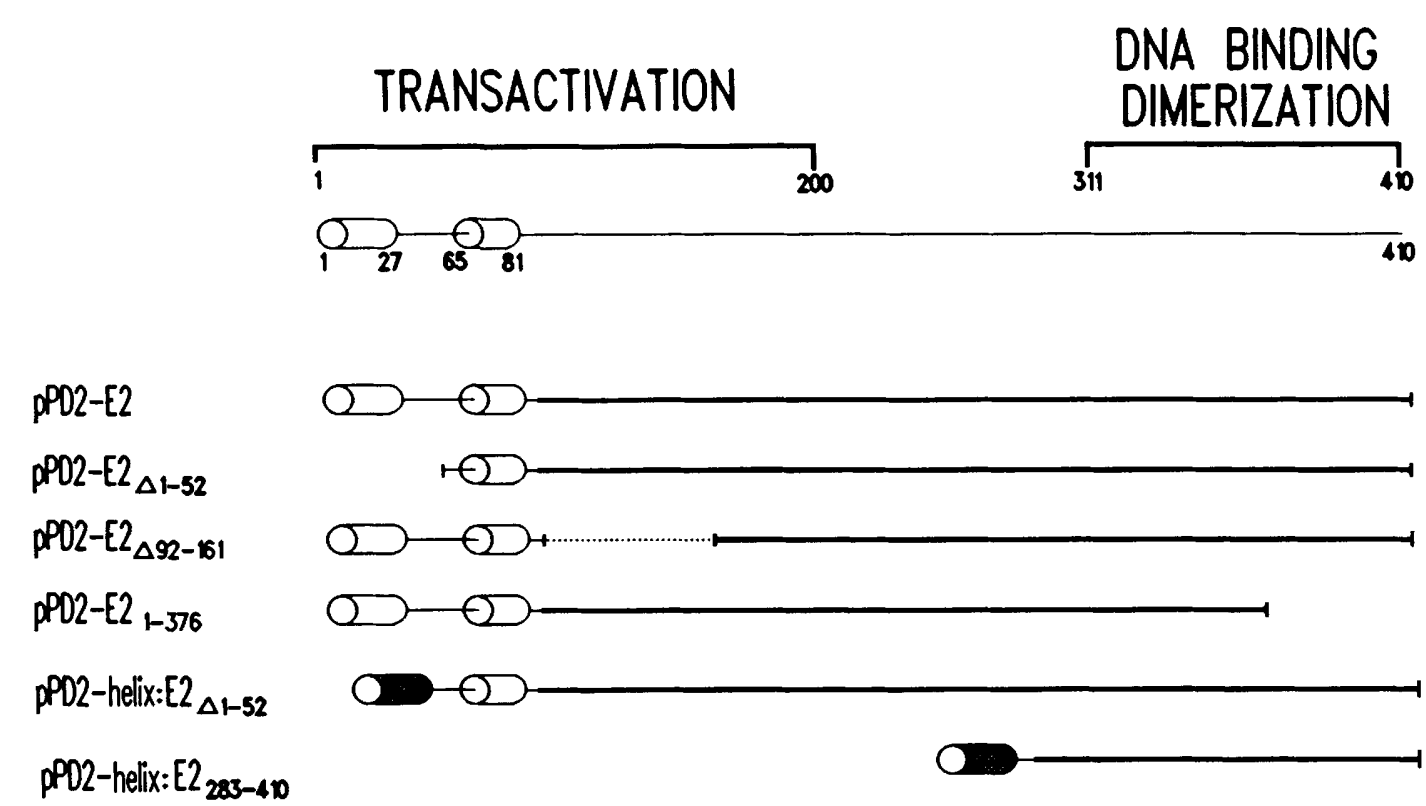

Figure 5. Structure of the mutated E2 proteins. (Top) Positions of the E2 protein domains that provide the trans-activational, DNAbinding, and dimerization properties (the numbers indicate the E2 ORF amino acid number). The open cylinders indicate the exact position (amino acid numbers indicated below) of the potential amphipathic domains present at the amino terminus of E2. The coding regions present in each of the E2 proteins encoded by the pPD2 plasmid series is depicted as a line drawing. The dotted line indicates the position of internally deleted portions of the E2 protein; the shaded cylinders indicate the position of the model amphipathic helix introduced using synthetic oligonucleotides (for details on each construct see Materials and methods). The E2 ORF amino acids deleted $(\triangle)$ or present in each pPD2-E2 plasmid are indicated in subscripts within the plasmid title, with the exception of pPD2-E2, which contains the unaltered $\mathrm{E} 2$ gene. 
Table 2. E2 trans-activation in S. cerevisiae $S X 4-6 a$

\begin{tabular}{|c|c|c|c|}
\hline & $\mathrm{DNA}_{1}$ & $\mathrm{DNA}_{2}$ & $\begin{array}{l}\beta \text {-Galactosidase } \\
\text { activity } \\
\text { (units) }^{\mathrm{a}}\end{array}$ \\
\hline 1. & $\mathrm{p} \Delta \mathrm{UAS}$ & $\mathrm{p} \triangle \mathrm{YAC}$ & 0.017 \\
\hline 2. & $\mathrm{p} \Delta \mathrm{UAS}: 1 \mathrm{mtf}$ & $\mathrm{p} \triangle \mathrm{YAC}$ & 0.080 \\
\hline 3. & $\mathrm{p} \Delta \mathrm{UAS}: 2 \mathrm{mtf}$ & $\mathrm{p} \triangle \mathrm{YAC}$ & 1.10 \\
\hline 4. & $\mathrm{p} \Delta \mathrm{UAS}$ & $\mathrm{p} \triangle \mathrm{YAC}-\mathrm{E} 2$ & 0.05 \\
\hline 5. & $\mathrm{p} \Delta \mathrm{UAS}: 1 \mathrm{mtf}$ & $\mathrm{p} \triangle \mathrm{YAC}-\mathrm{E} 2$ & 6.3 \\
\hline 6. & $\mathrm{p} \Delta \mathrm{UAS}: 2 \mathrm{mtf}$ & $\mathrm{p} \triangle \mathrm{YAC}-\mathrm{E} 2$ & 113.0 \\
\hline 7. & pHZ18 & $\mathrm{p} \triangle \mathrm{YAC}$ & 0.032 \\
\hline 8. & $\mathrm{pHZ} 18: 2 \mathrm{mtf}$ & $\mathrm{p} \triangle \mathrm{YAC}$ & 0.16 \\
\hline 9. & $\mathrm{pHZ} 18: 4 \mathrm{mtf}$ & $\mathrm{p} \triangle \mathrm{YAC}$ & 0.15 \\
\hline 10. & pHZ18 & $\mathrm{p} \triangle \mathrm{YAC}-\mathrm{E} 2$ & 0.055 \\
\hline 11. & $\mathrm{pHZ1} 8: 2 \mathrm{mtf}$ & $\mathrm{p} \triangle \mathrm{YAC}-\mathrm{E} 2$ & 1.20 \\
\hline 12. & $\mathrm{pHZ} 18: 4 \mathrm{mtf}$ & $\mathrm{p} \triangle \mathrm{YAC}-\mathrm{E} 2$ & 1.30 \\
\hline
\end{tabular}

a Cells (1 ml) from fresh overnight cultures grown in SD media were pelleted, washed once, and resuspended in $10 \mathrm{ml}$ of phosphate-depleted SD media. $\beta$-Galactosidase assays were performed after growth to an $\mathrm{OD}_{600}$ of $0.7-1.0$.

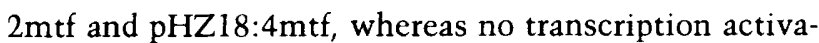
tion was observed by yeast UAS sequences introduced into this same intron site (Guarente and Hoar 1984). The

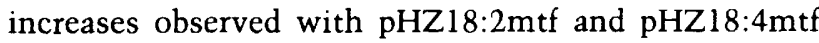
were significantly less than the 100 -fold increases seen with pDUAS: $2 \mathrm{mtf}$ (Table 2, line 6 versus 3 ). This difference in activation capacity, however, may reflect a similar position dependence of the E2 DNA-binding motifs seen in mammalian cells (Hawley-Nelson et al. 1988; Spalholz et al. 1988). In conclusion, the E2 enhancer may not be under the same stringent set of constraints with respect to position as are yeast UAS sequences.

Is the cooperativity imparted by multiple E2 DNAbinding motifs due to increased DNA-binding affinity?

The E2 protein trans-activated the $L A C Z$ gene 20 -fold higher when two DNA-binding motifs compared to one were present in cis (Table 1, line 10 versus 9). This cooperativity could be explained by either a higher affinity by E2 for its DNA-binding sites when present in tandem and/or the formation of an E2 complex made up of two tandemly bound E2 dimers, which has a far greater ability to trans-activate than a single E2 dimer bound at a single site. To test whether there is a measurable change in the binding affinity of E2, gel retardation studies were performed using the crude extracts from pPD2-E2 transfectant yeast grown under induced conditions (low $\mathrm{P}_{\mathrm{i}}$ ) and using oligonucleotide probes containing single or double E2 DNA-binding motifs (Fig. 6). The identification of the E2-specific complexes formed with these oligonucleotides has been established previously (Dostatni et al. 1988). In the presence of a single E2 target site, a single E2-specific complex was observed (Fig. 6A, C1), which reflects binding by an E2 homo- dimer to the $A C C N_{6} G G T$ motif. In the case of the double motif, occupation of a single site resulted in formation of $\mathrm{Cl}^{*}$, whereas occupancy of two sites gave rise to $\mathrm{C}^{*}$ (Fig. 6A). Quantitation of these complexes as a function of protein concentration (Fig. $6 \mathrm{~B}$ ) indicates that binding to the second E2 target site is favored by occupancy at the first site. Were there no cooperativity, the fraction of the two-motif probe bound at both sites, $\mathrm{C}_{2}$ *, should equal the square of the fraction of the two-motif probe bound at a single site, $\mathrm{Cl}^{*}$. The actual abundance of $\mathrm{C}_{2}{ }^{*}$ is three to four times that predicted value for any given protein concentration (see Fig. 6B). This in vitro analysis indicates that there is a slight but significant increase in the binding affinity by the $\mathrm{E} 2$ protein at the second bound site of an oligonucleotide containing tandem copies of the E2 DNA-binding motif. Comparison of the appearance and abundance of $\mathrm{Cl}^{*}$ as compared to $\mathrm{Cl}$, however, suggests that there is no increased affinity for binding to the first bound site of a tandem copy.

An alternative in vivo approach was taken to test whether there is an increased affinity for tandem E2 DNA-binding sites based on the prediction that this would lead to a disproportionately higher increase in the level of trans-activation for a double (pDUAS:2mtf) versus a single (pDUAS: $1 \mathrm{mtf}$ ) motif as E2 protein concentration is increased. E2 protein levels were modulated by growing yeast under defined media conditions in which the PHO5 promoter was uninduced (high $\mathrm{P}_{\mathrm{i}}$ ) or induced (low $P_{i}$ ). Direct evidence for the induction of the E2 protein levels under these conditions was provided by the gel retardation experiments (Fig. 3). With induction, the levels of E2-dependent expression increased eightand sevenfold in cells harboring either the single or double motif, respectively (Table 3 ). These results indicated no significant difference in the responsiveness of the $\beta$-galactosidase constructs at increased concentrations of E2, suggesting that changes in DNA-binding affinity could not account for the E2 cooperativity as assayed in vivo. We cannot discount, however, the possibility that factors other than E2 may be limiting under induced conditions, causing a suppression of E2 transcriptional activation in the case of pDUAS: $2 \mathrm{mtf}$. In summary, our data does not strongly support the role of increased DNA-binding affinity. It is more likely, therefore, that the cooperativity observed with tandemly duplicated E2 DNA-binding sites is due to an intrinsically higher trans-activational capacity by tandemly bound E2 dimers that greatly exceeds the additive capacity of singly bound E2 dimers.

\section{Discussion}

This study establishes that a mammalian virus transcriptional enhancer and its cognate trans-activator can function in $S$. cerevisiae. This observation provides the first example of a mammalian viral transcriptional factor functioning in yeast and supports the concepts that viral transcriptional control circuits have evolved to utilize host transcriptional machinery effectively and 


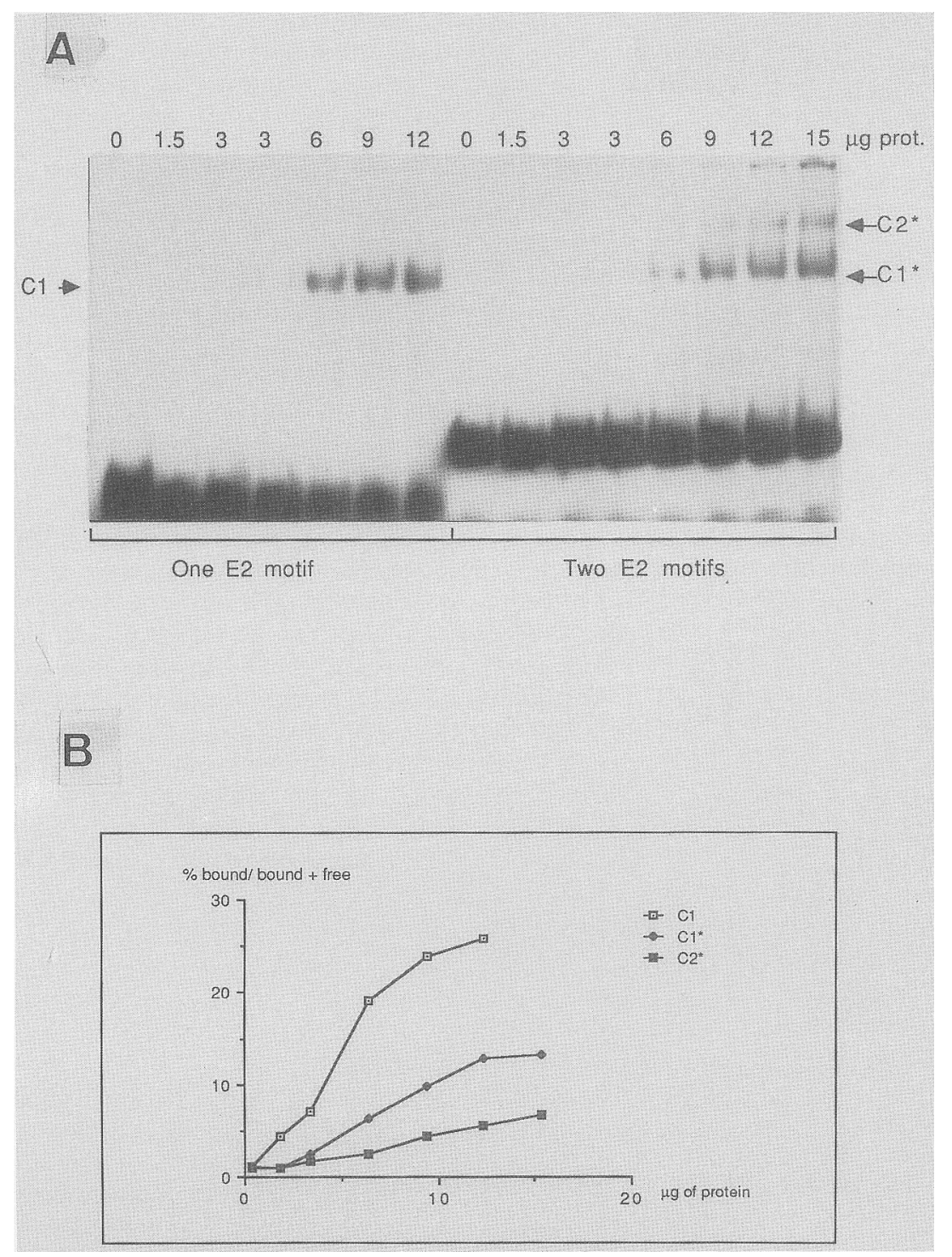

Figure 6. DNA-binding affinity. $|A|$ Gel retardation. The binding affinity E2 expressed in yeast for DNA probes containing one or two E2 DNA-binding sites is compared. Indicated amounts of extract protein from cells grown under low phosphate conditions were incubated, in the presence of $300 \mathrm{ng}$ of sonicated salmon sperm DNA and $1.5 \mu \mathrm{g}$ of poly $(\mathrm{dI}-\mathrm{dC})$, to prevent formation of the minor nonspecific bands observed in Fig. 3, with $2 \mathrm{ng}$ of either the single-motif probe used in Fig. 3 of the double-motif probe depicted below.

CTAGACCGAAAACGGTCGGGACCGAAAACGGTCTAG GATCTGGCTTTTGCCAGCCCTGGCTTTTGCCAGATC

The E2-specific complexes corresponding to binding at one or both E2 DNA-binding sites on the double-motif probe are labeled $\mathrm{Cl}^{\circ}$ and $\mathrm{C} 2^{\circ}$, respectively. $(B)$ Quantitation of E2-specific complexes. For each complex in $A \mid C 1$, $\mathrm{Cl}^{\circ}$, and $\left.\mathrm{C}^{\circ}\right)$ the radioactivity of the free versus bound probe was determined and the precent fraction bound was plotted as a function of protein concentration.
Table 3. Induction of E2 trans-activation

\begin{tabular}{|c|c|c|c|c|}
\hline & \multirow[b]{2}{*}{$\mathrm{DNA}_{1}$} & \multirow[b]{2}{*}{$\mathrm{DNA}_{2}$} & \multicolumn{2}{|c|}{$\begin{array}{l}\beta \text {-Galactosidase } \\
\text { activity (units) }\end{array}$} \\
\hline & & & high $P_{i}$ & low $P_{i}$ \\
\hline 1. & $\mathrm{p} \Delta U A S$ & - & $<0.05$ & $<0.05$ \\
\hline 2. & $\mathrm{p} \Delta \mathrm{UAS}: 1 \mathrm{mtf}$ & - & $<0.05$ & $<0.05$ \\
\hline 3. & $\mathrm{p} \Delta \mathrm{UAS}: 2 \mathrm{mtf}$ & - & $<0.05$ & $<0.05$ \\
\hline 4. & $\mathrm{p} \Delta \mathrm{UAS}$ & pPD2-E2 & $<0.05$ & $<0.05$ \\
\hline 5. & $\mathrm{p} \Delta \mathrm{UAS}: 1 \mathrm{mtf}$ & pPD2-E2 & 0.7 & 5.7 \\
\hline 6. & $\mathrm{p} \triangle \mathrm{UAS}: 2 \mathrm{mtf}$ & pPD2-E2 & 35 & 240 \\
\hline
\end{tabular}

Yeast was grown in defined minimal medium containing high (1000 mg/liter) or low (30 mg/liter) concentrations of phosphate $\left(\mathrm{P}_{\mathrm{i}}\right)$. Assays were performed after two successive growths in the indicated media at an $\mathrm{OD}_{600}$ of 0.6 . that this host machinery is conserved among lower and higher eukaryotes.

The basic requirements for the viral cis and trans elements were similar in yeast and in mammalian cells. The E2 DNA-binding sites were found to be sufficient in cis for E2 trans-activation and to function relatively independently of position, as has been documented in mammalian cells. The E2 protein expressed in yeast retained its capacity to bind to its DNA target sites. Correspondingly, a mutant E2 gene truncated within the DNA-binding domain of the E2 protein was defective in yeast, and deletion mutants removing part of the aminoterminal trans-activation domain were also defective in yeast, as shown previously in mammalian cells. Certain differences were seen in yeast, however, including the ability of a single E2 DNA-binding site to function in cis as an effective enhancer and the capacity for a model amphipathic helix to rescue partially a trans-activationdefective E2 mutant in yeast as discussed below.

Amphipathic helices or acid 'blobs' have been identified as potentially important protein 'structures' within 
the trans-activation domains of several eukaryotic transcriptional factors, and these domains have been postulated to be involved in protein-protein interactions with RNA polymerase or other transcriptional factors (reviewed in Guarente 1988). The E2 trans-activation contains two regions of potential amphipathic character at its amino terminus, within the trans-activation domain (Fig. 5). Deletion of the amino-terminal 52 amino acids, which includes one such amphipathic region, incapacitates E2 function in mammalian cells as well as in yeast (Table 1, line 11), indicating that this domain is essential for function. However, the lack of trans-activation activity in pPD2-E2 ${ }_{\triangle 92-161}$, which retains both regions of potential amphipathic character, indicates that these structures are not sufficient when linked directly to the DNA-binding/dimerization domain for providing all E2 trans-activation properties. This conclusion is supported, in part, by the behavior of pPD2-helix: E2 283-410, carrying the model amphipathic helix joined to the E2 DNA-binding domain, which, while somewhat capable of trans-activating pDUAS: $1 \mathrm{mtf}$, did not exhibit any cooperative trans-activation of p $\Delta U A S: 2 \mathrm{mtf}$. Barring differences in protein stability or improper 'presentation' of specific protein domains in the mutated or fusion E2 protein, these results suggest that regions of potential amphipathic character, although necessary, are not sufficient for normal E2 trans-activator function. Interestingly, the model amphipathic helix does not rescue, to any measureable extent, the trans-activation defect of these same E2 deletion mutants in mammalian cells (A. McBride and P. Howley, unpubl.), suggesting that there are likely to be mechanistic differences between the transcriptional machinery of higher and lower eukaryotes.

Cooperativity, the synergistic effect of multiple enhancer core sequences on transcriptional activation, is a common feature among transcriptional enhancers (Ondek et al. 1988). In mammalian cells there is a requirement for at least two E2 DNA-binding sites for enhancer activity, and cooperativity between E2 DNAbinding motifs is evidenced by the 10-fold increase in enhancer activity for four copies of the motif versus that for two copies (Spalholz et al. 1988). In this study cooperativity was demonstrated in yeast in which two copies of the E2 motif gave 20 -fold higher levels of $\beta$-galactosidase activity than a single motif (Tables 1 and 2). As indicated by our DNA affinity studies (Fig. 6, Table 3), we believe that this cooperativity must largely be due to an increased capacity for tandemly bound E2 dimers to trans-activate, compared to the additive capacity of individually bound dimers. This raises the possibility that E2 dimers may interact with one another, either directly or through complexes with cellular factors. The properties of various E2 mutant proteins suggest that cooperativity may, at least in part, be a property of the trans-activation domain, a region of $\mathrm{E} 2$ that is predicted to play a role in such protein-protein interactions. Specifically, the protein encoded in pPD2-helix:E2 ${ }_{\Delta 1-52}$, in which the first 52 amino acids of the $E 2$ protein are replaced with a model amphipathic helix, does not exhibit cooperativity between multiple DNA-binding motifs, although it does exhibit sequence-specific trans-activation. The aminoterminal 52 amino acids comprise a portion of the E2 trans-activation domain, as evident from the properties of pPD2-E2 $2_{\Delta 1-52}$ in yeast and in mammalian cells (McBride et al. 1989). These observations indicate that the integrity of the amino terminus is required for cooperativity and, furthermore, that regions of potential amphipathic helix that exist in these first 52 amino acids are not sufficient for providing the cooperativity. Further analysis of this region should provide interesting insights into the protein-coding requirements for cooperativity and perhaps into the mechanism for cooperativity.

An important feature of studying mammalian viral transcription factors in yeast is the potential for using yeast genetics. Testing of yeast strains defective in particular transcription factors may provide insight into functional interactions between mammalian factors and genetically defined yeast factors. The E2 ORF and its transcriptional regulatory capacity are conserved among all of the papilloma vinuses studied so far (Cripe et al. 1987; Hirochika et al. 1987; Phelps and Howley 1987; Thierry and Yaniv 1987; Giri and Yaniv 1988a). Initial experiments confirm that at least one other papilloma virus E2 trans-activator, that of human papilloma virus type 16 (HPV-16), also trans-activates in S. cerevisiae (Munger et al. unpubl.). Thus, yeast may provide a system for comparing the host factors required for transactivation by the $\mathrm{E} 2$ proteins of different papilloma viruses.

\section{Materials and methods}

Construction of plasmids

p $\triangle$ UAS is a $2 \mu$-derived plasmid that contains the $L A C Z$ gene driven by the $C Y C 1$ promoter. The upstream activation sequence of the promoter has been removed (nucleotides -312 to -178 ) and replaced by a unique $X$ hol site (Guarente and Mason 1983). Double-stranded, synthetic oligonucleotides, containing either a single or a double $\mathrm{ACCN}_{6} \mathrm{GGT}$ motif /sequences illustrated in Fig. 1A), were inserted into the $X$ hol site to give rise to $\mathrm{p} \Delta \mathrm{UAS}: 1 \mathrm{mtf}$ or $\mathrm{p} \Delta \mathrm{UAS}: 2 \mathrm{mtf}$, respectively. The same oligonucleotides, containing single or double motifs, were also inserted into the unique Sall site in pHZ18 (Teem and Rosbash 1983) within the intron separating exons 1 and 2 in rp5l, giving pHZ18:2mtf or pHZ18:4mtf, respectively (see Fig. 1A). The plasmid, pPD2 (see Fig. 1B), is a $2 \mu$ vector that contains the inducible PHO5 promoter and terminator. A unique HindIII site, located between the promoter and terminator, allows foreign genes to be inserted and expressed under the control of the PHO5 promoter. DNA fragments containing the BPV-1 E2 ORF, or mutated versions, were cloned in PTZ18/19 vectors and have been described previously (McBride et al. 1988, 1989). pTZE $_{\mathrm{mHm}}$ was generated by inserting a BamHI-HindIIIBamHI adaptor into the BamHI site of $\mathrm{pTZE} 2_{\mathrm{m}}$. A HindIII fragment containing the entire E2 ORF was then inserted into pPD2. Fragments containing mutated versions of the E2 ORF were cleaved from the pTZ vector by HindIII and EcoRI, the ends filled in with the Klenow fragment of DNA polymerase I and inserted into the blunt-ended HindIII site of pPD2. In pPD2E2-helix:E2 ${ }_{\Delta 1-52}$ and pPD2E2-helix: ${ }_{\Delta 283-410}$, synthetic oligonucleotides encoding an initiation methionine codon fol- 
lowed by the previously described amphipathic helix amino acid sequence, $(\mathrm{Glu}, \mathrm{Leu}, \mathrm{G} \ln )_{3} \mathrm{Ala}, \mathrm{Leu}, \mathrm{Leu}(\mathrm{Gln})_{3}$ were ligated to the AvrII or KpnI site in the E2 ORF, respectively. The ARS/ centromere vector, $\mathrm{p} \triangle \mathrm{YAC}$, was constructed from a larger plasmid, pYAC3 (Burke et al. 1987). As shown in Figure 1C, pYAC3 was cleaved with $\mathrm{XhoI}$ and Sall and religated to generate a vector containing $A R S 1$ and $C E N 4$ sequences and the TRP1-selectable marker. A BamHI fragment from pPD2-E2, containing the $P H O 5$ promoter and the wild-type E2 ORF, was made blunt with the Klenow fragment of DNA polymerase I and inserted into the SmaI cloning site of $\triangle \mathrm{YAC}$, to generate pDYAC-E2.

\section{Yeast strains, transfection, and $L A C Z$ expression}

Yeast strains BWG1-7a: a;leu2,2-leu2,-11; his4-his519; ade1ade100; ura3-ura52 (Guarente and Masson 1983) and SX4-6A: a; ade2,1; his3,532; trp1,289; ura3,1-2; ino $^{-}$; cana $^{\mathrm{R}}$ (gift from Dr. B. Dujon; Institut Pasteur, Paris) were grown in SD media (Sherman et al. 1986), supplemented with required metabolites. Transfections were performed using the previously described procedure (Ito et al. 1983) and cells were plated on SD-agar plates. To detect $L A C Z$ expression, yeast was streaked onto a nitrocellulose membrane, which was then placed onto a SDagar plate and incubated at $30^{\circ} \mathrm{C}$ for $48 \mathrm{hr}$. The nitrocellulose membrane was then transferred to an agar plate containing the chromogenic substrate (X-gal), in which the phosphate buffer was replaced with $30 \mathrm{~mm}$ MOPS $(\mathrm{pH} 7.0)$ and incubated for an additional $5 \mathrm{hr}$. $L A C Z$ expression was measured in liquid cultures grown in either defined medium (Lillie and Pringle 1980) or phosphate-depleted SD media (according to protocol described for depletion of YPD media in Rubin 1973), as indicated, using the chromogenic substrate ONPG (Guarente 1983). Experiments were performed in triplicate, and values attained represent the mean. On average, levels of $\beta$-galactosidase expression were two- to threefold higher under the induced conditions when cells were grown in the defined minimal media as compared to the phosphate-depleted SD media (e.g., cf. Table 3, line 6 to Table 1, line 10 ).

\section{Immunoprecipitation}

Cells were grown in $20-\mathrm{ml}$ cultures to early log phase under conditions of high or low phosphate, as described above. Cells were labeled for $10 \mathrm{~min}$ with $\left.{ }^{35} \mathrm{~S}\right)$ methionine $(1200 \mathrm{Ci} / \mathrm{mole})$ at a concentration of $20 \mu \mathrm{Ci} / \mathrm{ml}$. Cells were washed twice in cold phosphate-buffered saline and resuspended in $1 \mathrm{ml}$ RIPA [20 mM MOPS ( $\mathrm{pH} 7.0$ ), $150 \mathrm{~mm} \mathrm{NaCl}, 1 \mathrm{~mm}$ EDTA, $0.1 \%$ SDS, $1 \%$ NP-40, $1 \%$ sodium deoxycholate] containing protease inhibitors phenylmethylsulfonyl fluoride (PMSF), TCLK, TPCK, leupeptin, and aprotinin. Glass beads (0.7 gram) were added, and the cells were disnupted by several cycles of vortexing and cooling on ice. The lysate was clarified by centrifugation, and E2 polypeptides were immunoprecipitated using an antipeptide antisera, SRQE, which has been characterized previously (McBride et al. 1988) and analyzed by SDS-PAGE.

\section{Gel retardation assays}

Yeast extracts for band-shift assays were prepared as described previously (Arcangioli and Lescure 1985). Cells were grown at $30^{\circ} \mathrm{C}$ in $50-\mathrm{ml}$ cultures under conditions of low or high phosphate (see footnote to Table 3 ) to an $\mathrm{OD}_{600}=0.4-0.6$. They were harvested by centrifugation and washed with buffer $\mathrm{A}$ [100 $\mathrm{mm}$ Tris $\left\langle\mathrm{pH} 8.0\right.$ ), $400 \mathrm{~mm}$ ammonium sulfate, $10 \mathrm{mM} \mathrm{MgCl}_{2}, 7$ $\mathrm{mM} \beta$-mercaptoethanol, and $10 \%$ glycerol]. The cell pellet was resuspended with an equal volume of buffer $A$ containing $1 \mathrm{mM}$ PMSF, $0.5 \mu \mathrm{M}$ leupeptin, $0.1 \mu \mathrm{M}$ pepstatin and then disrupted at $0^{\circ} \mathrm{C}$ by vortexing at maximal velocity with an equal volume of $0.45-\mathrm{mm}$-diam. glass beads. The extracts were cleared by centrifugation for $1 \mathrm{hr}$ at $100,000 \mathrm{~g}$. The supernatant was collected and precipitated with $50 \%$ ammonium sulfate, and the pellet was resuspended in buffer $\mathrm{O}$ [20 mM HEPES ( $\mathrm{pH} 8.0), 0.1 \mathrm{~mm}$ EDTA, $1 \mathrm{mM}$ PMSF, $0.5 \mu \mathrm{M}$ leupeptin, $0.1 \mu \mathrm{M}$ pepstatin, 20\% glycerol, and $7 \mathrm{mM} \beta$-mercaptoethanol]. The final extracts had protein concentrations of $5-15 \mathrm{mg} / \mathrm{ml}$.

DNA-binding reactions were carried out in a volume of $20 \mu \mathrm{l}$ in the presence of $0.5 \times$ buffer $\mathrm{O}, 500 \mathrm{ng}-1.5 \mu \mathrm{g}$ of doublestranded poly $(\mathrm{dI}-\mathrm{dC}), 100-300 \mathrm{ng}$ of sonicated salmon sperm DNA, $4 \mathrm{mM} \mathrm{MgCl} 2,4 \mathrm{mM}$ spermidine, $0.1 \% \mathrm{NP}-40$ (only in the experiment reported in Fig. 31, and $0.5-2$ ng of 32 P-end-labeled double-stranded DNA oligonucleotide. From 0.5 to $12 \mu \mathrm{g}$ of protein extract was added, and incubation was carried out at $0^{\circ} \mathrm{C}$ for $5 \mathrm{~min}$. The reaction mixture was loaded immediately onto a low-ionic-strength $6 \%$ acrylamide $(29: 1)$ gel containing $0.25 \times$ TBE. After electrophoresis at 12 volts $/ \mathrm{cm}$, the gel was dried and autoradiographed. For precise quantitation, radioactive bands were excised and counted.

\section{Acknowledgments}

This work was supported, in part, by a NATO grant for International Collaboration in Research to P.H. and M.Y., as well as grants from the Association pour la Recherche contre le Cancer, the Ligue Nationale Française contre le cancer, and the Fondation pour la recherche médicale to M.Y. N.D. is supported by a fellowship from the ARC. We wish to thank the laboratory of Dr. R. Dhar for helpful advice, Drs. B. Dujon, P. Dehoux, L. Guarente, and P. Yeh for plasmids and yeast strains, R. Sousa for the plasmid, pDUAS, J. Byrne for synthetic oligonucleotides, Dr. F. Thierry for comments, and C. Comlish for expert editorial assistance.

\section{References}

Allison, L.A., J. Wong, V.D. Fitzpatrick, M. Moyles, and C.J. Ingles. 1988. The C-terminal domain of the largest subunit of RNA pol II of Sacchromyces cerevisiae, Drosophila melanogaster and mammals: a conserved structure with an essential function. Mol. Cell. Biol. 8: 321-329.

Androphy, E.J., D.R. Lowy, and J.T. Schiller. 1987. Bovine papillomavinus E2 trans-acting gene product binds to specific sites in papilloma virus DNA. Nature 325: 70-73.

Arcangioli, B. and B. Lescure. 1985. Identification of proteins involved in regulation of yeast iso-1-cytochrome $C$ expression by oxygen. EMBO I. 4: 2627-2633.

Burke, D., G. Carle, and M. Olson. 1987. Cloning of large segments of exogenous DNA into yeast by means of artificial chromosome vectors. Science 236: 806-812.

Chodosh, L.A., J. Olesan, S. Han, A.S. Baldwin, L. Guarente, and P. Sharp. 1988. A yeast and a human CCAAT-binding protein have heterologous subunits that are functionally interchangeable. Cell 53: 25-35.

Cripe, T.P., T.H. Haugen, J.P. Turk, F. Tabatabai, P.G. Scmid III, M. Durst, L. Gissman, A. Roman, and L. Turek. 1987. Transcriptional regulation of the human papilloma virus type 16 E6-E7 promoter by a kerotinocyte-dependent enhancer, and by viral E2 trans-activator and repressor gene products: implications for cervical carcinogenesis. EMBO $/$. 6: 3745-3753.

Dostatni, N., F. Thierry, and M. Yaniv. 1988. A dimer of BPV-1 E2 protein containing a protease resistant core interacts with its DNA target. $E M B O$ I. 7:3807-3816. 
Giniger, G.M. and M. Ptashne. 1987. Transcription in yeast activitated by a putative amphipathic $\alpha$ helix linked to a DNA binding unit. Nature 330: 670-672.

Giri, I. and M. Yaniv. 1988a. Study of the E2 gene product of the cottontail rabbit papillomavirus reveals a common mechanism of trans-activation among the papillomaviruses. I. Virol. 62: 1573-1581.

- 1988b. Structural and mutational analysis of E2 transactivating proteins of papillomaviruses reveals three distinct functional domain. EMBO I. 7: 2823-2829.

Guarente, L. 1983. Yeast promoters and $L A C Z$ fusions designed to study expression of cloned genes in yeast. Methods Enzymol. 101: $181-191$.

- 1988. UASs and enhancers: Common mechanism of transcriptional transactivation in yeast and mammals. Cell 52: 303-305.

Guarente, L. and E. Hoar. 1984. Upstream activation sites of the CTC1 gene of $S$. cerevisiae are active when inverted but not when placed downstream of the TATA box. Proc. Natl. Acad. Sci. 81: 7860-7864.

Guarente, L. and T. Mason. 1983. Heme regulate transcription of the CTC1 gene of Saccharomyces cerevisiae via an upstream activation site. Cell 32: 1279-1286.

Harrison, S.M., K.L. Gearing, S.Y. Kim, A.J. Kingsman, and S.M. Kingsman. 1987. Multiple cis-active elements in the long control region of bovine papillomavirus type-1 (BPV-1). $\mathrm{Nu}$ cleic Acids Res. 15: 10267-10284.

Harshman, K.O., W.S. Moyo-Rowley, and C.S. Parker. 1988. Transcription activation by the SV40 AP-1 recognition element in yeast is mediated by a factor similar to AP-1 but distinct from GCN4. Cell 53: 321-330.

Haugen, T.H., T.P. Cripe, G.D. Ginder, M. Karin, and L.P. Turek. 1987. Trans-activation of an upstream early gene promoter of bovine papilloma virus- 1 by a product of the viral E2 gene. $E M B O$ I. 6: 145-152.

Hawley-Nelson, P., E.J. Androphy, D.R. Lowy, and J.T. Schiller. 1988. The specific DNA recognition sequence of the bovine papillomavirus E2 protein in an E2-dependent enhancer. EMBO I. 7: 525-531.

Hermonat, P.L., B.A. Spalholz, and P.M. Howley. 1988. The bovine papillomavirus $P_{2443}$ promoter is E2 trans-responsive: evidence for $\mathrm{E} 2$ autoregulation. $E M B O$ J. 7: 2815-2822.

Hirochika, H., T.R. Broker, and L.T. Chow. 1987. Enhancers and trans-acting E2 transcriptional factors of papillomaviruses. J. Virol. 61: 2599-2606.

Hirochika, H., R. Hirochika, T. Broker, and L.T. Chow. 1988. Functional mapping of the human papillomavinus type II transcriptional enhancer and its interaction with the transacting E2 proteins. Genes Dev. 2: 54-67.

Hubbert, N.L., J.T. Schiller, D.R. Lowy, and E.J. Androphy. 1988. Bovine papillomavirus transformed cells contain multiple E2 proteins. Proc. Natl. Acad. Sci. 85: 5864-5865.

Ito, H., Y. Jukuda, K. Murata, and A. Kimura. 1983. Transformation of intact yeast cells treated with alkalications. I. Bacteriol. 153: 163-168.

Kakidani, H. and M. Ptashne. 1988. Gal4 activates gene expression in mammalian cells. Cell 52: 161-167.

Lambert, P.F., B.A. Spalholz, and P.M. Howley. 1987a. A transcriptional repressor encoded by BPVI shares a common carboxy terminal domain with the E3 transactivator. Cell 50: $69-78$.

-1987b. Evidence that bovine papillomavinus type 1 may encode a negative transcriptional regulatory factor. Cancer Cells 5: 15-22.

Lillie, S. and J. Pringle. 1980. Reserve carbohydrate metabolism in $S$. cerevisiae: response to nutrient limitation. J. Bacteriol. 143: $1384-1394$.
McBride, A.A., R. Schlegel, and P.M. Howley. 1988. The carboxy-terminal domain shared by the bovine papillomavirus E2 transactivator and repressor proteins contains a specific DNA binding activity. EMBO I. 7: 533-539.

McBride, A.A., J.C. Byrne, and P.M. Howley. 1989. E2 polypeptides encoded by bovine papillomavirus I form dimers through the carboxyl-terminal DNA binding domain: Transactivation is mediated through the conserved amino-terminal domain. Proc. Natl. Acad. Sci. 86: 510-514.

Metzger, O., J.H. White, and P. Chambon. 1988. The human oestrogen receptor functions in yeast. Nature 334: 31-36.

Moskaluk, C. and D. Bastia. 1987. The E2 'gene' of bovine papillomavirus encodes an enhancer-binding protein. Proc. Natl. Acad. Sci. 84: 1215-1218.

Ondek, B., L. Gloss, and W. Herr. 1988. The SV40 enhancer contains two distinct levels of organization. Nature 333: $40-45$.

Phelps, W.C. and P.M. Howley. 1987. Transcription transactivation by the human papillomavirus type 16 E2 gene product. J. Virol. 61: 1630-1638.

Rogers, D.T., J.M. Lemine, and K.A. Bostian. 1982. Acid phosphatase polypeptides in Saccharomyces cerevisiae are encoded by differentially regulated multy gene family. Proc. Natl. Acad. Sci. 79: 2157-2161.

Rubin, G.M. 1973. The nucleotide sequence of the $S$. cerevisiae 5.8S ribosomal RNA. J. Biol. Chem. 248: 3860-3875.

Schena, M. and K.R. Yamamoto. 1988. Mammalian glucocorticoid receptor derivatives enhance transcription in yeast. Science 241: 965-967.

Sherman, F., G.H. Fink, and J.B. Hicks. 1986. Methods in yeast genetics, p. 164. Cold Spring Harbor Laboratory, Cold Spring Harbor, New York.

Spalholz, B.A., Y.C. Yang, and P.M. Howley. 1985. Transactivation of a bovine papillomavirus transcriptional regulatory element by the E2 gene product. Cell 42: 183-191.

Spalholz, B.A., P.F. Lambert, C.L. Yee, and P.M. Howley. 1987. Bovine papillomavinus transcriptional regulation: localization of the E2-responsive elements of the long control region. J. Virol. 61: 2128-2137.

Spalholz, B., J. Byrne, and P. Howley. 1988. Evidence for cooperativity between $\mathrm{E} 2$ binding sites in $\mathrm{E} 2$ trans-regulation ofbovine papillomavirus type 1 . J. Virol. 62: 3143-3150.

Struhl, K. 1987. The DNA-binding domains of the jun oncoprotein and the yeast GCN4 transcriptional activator protein are functionally homologous. Cell 50: 841-846.

Teem, J.L. and M. Rosbash. 1983. Expression of $\beta$-galactosidase gene containing the ribosomal protein 51 intron is sensitive to the rna2 mutation of yeast. Proc. Natl. Acad. Sci. 80: $4403-4407$.

Thierry, F. and M. Yaniv. 1987. The BPV-1 E2 trans-acting protein can be either an activator or a repressor of the HPV-18 regulatory region. EMBO I. 6: 3391-3397.

Webster, N., J.R. Jin, S. Green, M. Hollis, and P. Chambon. 1988. The yeast UAS is a transcription enhancer in human HeLa cells in the presence of the GAL4 transactivator. Cell 52: $168-178$.

Yang, Y.C., B.A. Spalholz, M.S. Rabson, and P.M. Howley. 1985. Dissociation of transforming and trans-activation functions for bovine papillomavirus type 1. Nature 318: $575-577$. 


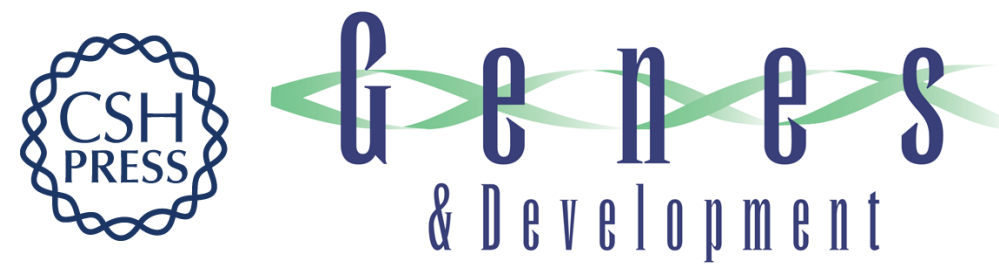

\section{Functional analysis of the papilloma virus E2 trans-activator in Saccharomyces cerevisiae.}

P F Lambert, N Dostatni, A A McBride, et al.

Genes Dev. 1989, 3:

Access the most recent version at doi:10.1101/gad.3.1.38

References This article cites 44 articles, 18 of which can be accessed free at:

http://genesdev.cshlp.org/content/3/1/38.full.html\#ref-list-1

License

Email Alerting

Service

Receive free email alerts when new articles cite this article - sign up in the box at the top right corner of the article or click here.

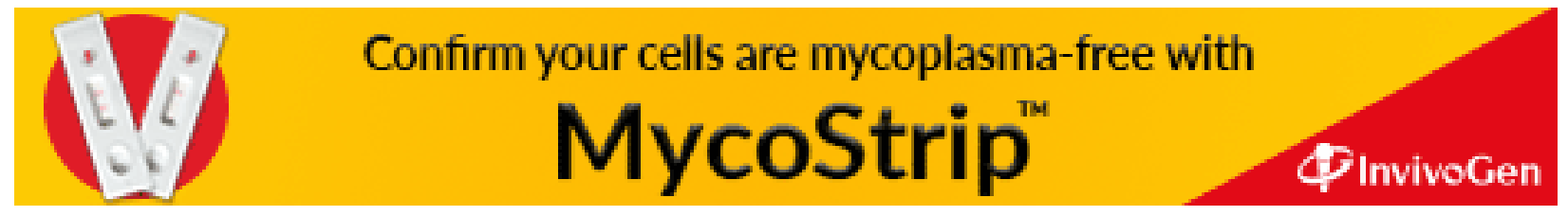

